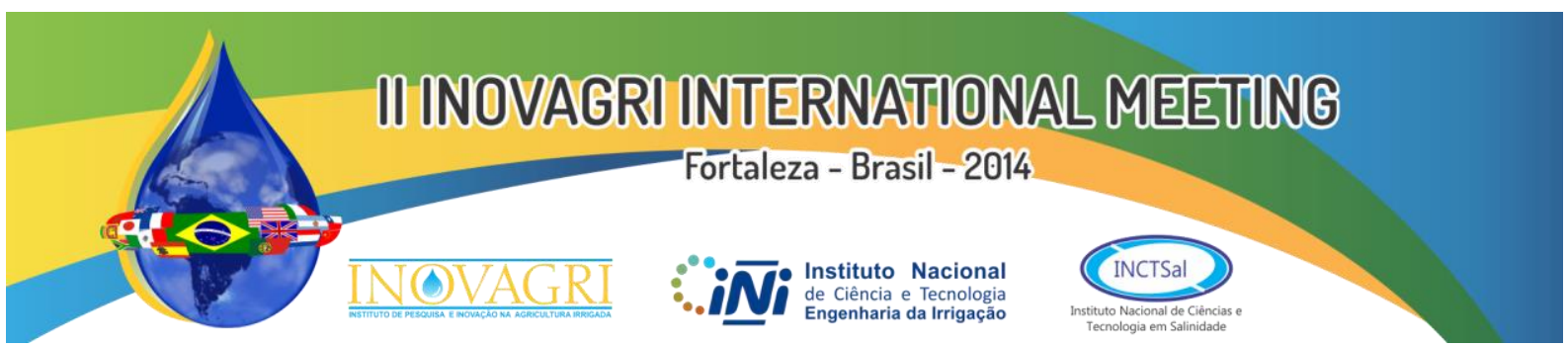

http://dx.doi.org/10.12702/ii.inovagri.2014-a028

\title{
ESTIMATIVA DOS FLUXOS EVAPOTRANSPIRATÓRIOS NA FLORESTA NACIONAL DO TAPAJÓS E ENTORNO A PARTIR DE IMAGENS DE SATÉLITE
}

\author{
J. F. Leivas ${ }^{1}$, A. H. de C. Teixeira ${ }^{1}$, R. G. Andrade ${ }^{1}$
}

RESUMO: Diante do crescente interesse em assuntos ligados ao monitoramento e conservação dos recursos florestais, a obtenção de parâmetros biofísicos como albedo $(\alpha)$ e evapotranspiração (ET), representa um desafio para a compreensão do balanço de energia da superfície e a atmosfera em biomas tropicais. Este estudo avaliou esses parâmetros na Floresta Nacional do Tapajós (FLONA), na Amazônia Paraense. O algoritmo SAFER (Simple Algorithm For Evapotranspiration Retrieving) foi utilizado juntamente com imagens do satélite Landsat-5/TM e um buffer no entorno da FLONA para analisar áreas de pastagem e agricultura nas imagens de satélite. O albedo da superfície apresentou valores médios crescentes entre datas analisadas, o que indica expansão de áreas agrícolas no entorno da FLONA. Em 2009, observou-se maior temperatura da superfície, nas áreas de expansão agrícola. O valor médio diário da ET estimada foi de $3,38 \mathrm{~mm} \mathrm{~d}^{-1}$ nas áreas agrícolas e de 4,78 mm.d $\mathrm{d}^{-1}$ na Floresta Nacional do Tapajós. Conclui-se que mesmo com baixa densidade de estações meteorológicas na Amazônia, foi possível avaliar a dinâmica espaço-temporal da ação antrópica no entorno da FLONA, contribuindo para avaliações dos impactos da expansão agrícola nessa região.

PALAVRAS-CHAVE: evapotranspiração, Amazônia, SAFER, sensoriamento remoto

\section{EVAPOTRANSPIRATION FLOWS ESTIMATE AT NATIONAL FOREST TAPAJÓS AND SURROUNDING FROM SATELLITE IMAGES}

SUMMARY: Given the increasing interest in issues related to monitoring and conservation of forest resources, obtaining biophysical parameters such as albedo ( $\alpha$ ), surface temperature (TST) and evapotranspiration (ET), is a challenge to understanding of the energy balance of the surface and atmosphere in tropical biomes. This study assessed the spatiotemporal dynamics these parameters on the Tapajós National Forest (FLONA), in the Amazon Pará state. The algorithm SAFER (Simplified Algorithm For Evapotranspiration Retrieving) was used with satellite images and Landsat-5/TM a buffer around of the FLONA to analyze pasture and agriculture areas in satellite images. The surface albedo had average values increasing between dates analyzed which indicates expansion of agricultural land in the vicinity of the National Forest. In 2009, there was a higher surface temperature in the areas of agricultural expansion. The average daily value of the estimated ET was $3.38 \mathrm{~mm} \mathrm{~d}-1$ agricultural areas and $4.78 \mathrm{~mm} . \mathrm{d}-1$ in the Tapajós National Forest. It was concluded that even with low density of meteorological stations in the Amazon, been possible evaluate the spatiotemporal dynamics of anthropogenic activities in the surrounding of the National Forest, contributing evaluations of impacts agricultural expansion in this region.

KEYWORDS: evapotranspiration, Amazonia, SAFER, remote sensing

\footnotetext{
${ }^{1}$ Pesquisador, Embrapa Monitoramento por Satélite - CNPM/, Campinas - SP. Fone (19)32116200. E-mails: janice.leivas@embrapa.br ; heriberto.teixeira@embrapa.br ; ricardo.andrade@embrapa.br
}
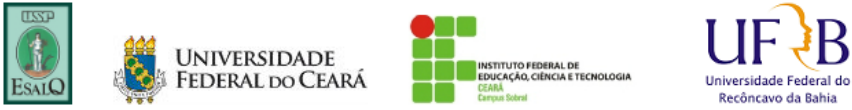


\section{INTRODUÇÃO}

A Floresta Amazônica representa uma importante fonte de calor e de vapor de água para a atmosfera, onde o calor latente liberado no processo de evapotranspiração influencia na circulação atmosférica nos trópicos e o vapor de água contribui para a geração de precipitação regional (DIRMEYER e BRUBAKER, 2007).

A Floresta Nacional do Tapajós (FLONA) apresenta áreas de floresta primária cercada, principalmente à leste da BR 163 , por diversas áreas nas quais tem sido afetada por atividades humanas, como agricultura e pecuária. Geralmente processos como corte e queima foram e ainda são utilizados na abertura de novas áreas. Em alguns locais, os moradores abandonaram as áreas que se encontram atualmente em processo de regeneração.

Inúmeras atividades econômicas estão adentrando na região Amazônica, provocando alterações que tornam imprevisíveis a intensidade dos impactos causados por esse novo ciclo de produção. $\mathrm{O}$ avanço da fronteira agrícola sobre áreas naturais, removendo a cobertura vegetal natural, e mesmo o impacto da utilização de novas técnicas de produção e novas formas de manejo tem consequências imprevisíveis nos processos conduzidos por microorganismos e pelas novas formas de cultura que se estabelecem dentro da região (MACHADO, 2012).

$\mathrm{O}$ crescente interesse em assuntos ligados ao manejo e monitoramento dos recursos florestais tem aumentado a demanda por mapeamentos da cobertura vegetal, em escalas regionais ou até mesmo globais (DEFRIES e BELWARD, 2000; SHIMABUKURO e RUDORFF, 2000). Nos últimos anos, o sensoriamento remoto tem se tornado importante ferramenta para análise e monitoramento da cobertura vegetal.

O gerenciamento dos recursos hídricos é imprescindível para a preservação dos recursos naturais. Sabe-se que o setor agrícola utiliza a maior parte da água disponível nos rios, lagos e reservas aquíferas. Diante disso, o conhecimento da evapotranspiração tem fundamental importância para o planejamento e uso racional da água, já que sabendo a quantidade de água perdida para a atmosfera pelas culturas é possível estimar as necessidades hídricas evitando excessos e déficits hídricos. Os métodos convencionais para obtenção da ET fornecem informações pontuais e de elevado custo. Para preencher esta lacuna, o sensoriamento remoto tem sido amplamente utilizado para obtenção dos componentes do balanço de energia e da evapotranspiração, em escala regional, conforme estudos realizados por vários autores.

Mudanças ambientais atuais podem afetar negativamente os seres humanos na Amazônia e em outros locais. Estas mudanças incluem a perda da capacidade produtiva dos ecossistemas, redução de ciclagem d'água devido à perda de evapotranspiração, com perda consequente de precipitação, tanto na Amazônia como nas partes não amazônicas do Brasil que atualmente sofrem de precipitação insuficiente (FEARNSIDE, 2003).

O objetivo deste estudo foi utilizar os dados de estações meteorológicas e imagens de satélite para analisar os parâmetros biofísicos como albedo e evapotranspiração da Floresta Nacional do Tapajós, utilizando dados multitemporais Landsat-5/TM.

\section{MATERIAL E MÉTODOS}

A Floresta Nacional do Tapajós está localizada no Estado do Pará $\left(54^{\circ} 58^{\prime} \mathrm{W}, 2^{\circ} 51^{\prime}\right.$ S) e possui uma área de 590.000 ha. (Figura 1). De acordo com a classificação de Köppen, o clima é do tipo $\mathrm{AmW}$ (clima tropical com temperatura média do dia mais frio do ano superior a $18{ }^{\circ} \mathrm{C}$ ). Temperatura, umidade relativa e precipitação pluviométrica são $25^{\circ} \mathrm{C}, 85 \%$, e $1920 \mathrm{~mm}$ por ano, respectivamente (PAROTTA et al., 1995). Solos são predominantemente pobres em nutrientes (oxisolos) com areia com baixo teor de matéria orgânica (SILVER et al., 2000). 


\section{J. F. Leivas et al.}

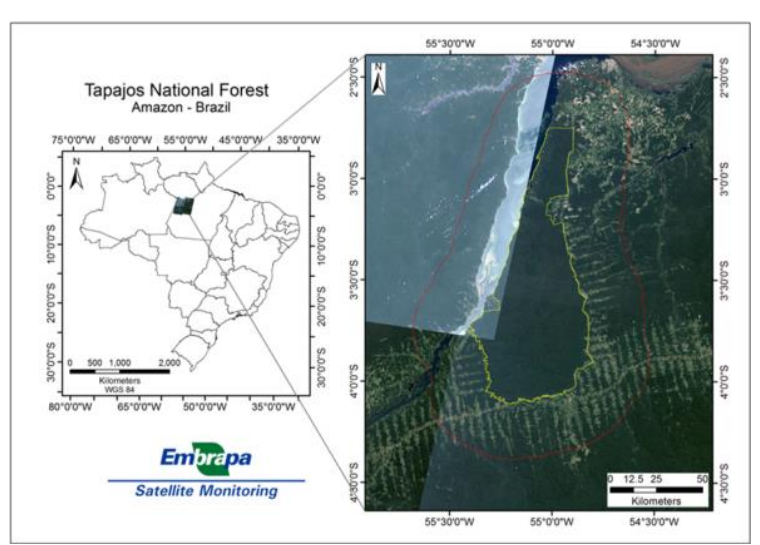

Figura 1. Área de estudo - Floresta Nacional do Tapajós, Pará, Brasil (delimitada pelo contorno amarelo e área no entorno de $30 \mathrm{Km}$, delimitada pela linha vermelha).

Para cobrir a área ocupada pela FLONA foram necessárias quatro imagens do satélite Landsat-5 Thematic Mapper (TM), órbitas 227/228 e pontos 62/63 adquiridas em períodos diferentes: 1989 (22 de agosto e 28 de julho) e 2009 ( 3 de julho, 12 de julho, 28 de julho e 23 de outubro). Para o georreferenciamento das imagens foi utilizado o mosaico GeoCover. Devido à alta nebulosidade na Amazônia, há poucas imagens disponíveis no período de estudo (1989 a 2009) com baixa porcentagem de cobertura de nuvens.

A partir da aplicação do modelo SAFER (Simple Algorithm For Evapotranspiration Retrieving) foi estimado albedo e a evapotranspiração. As etapas de processamento do algoritmo podem ser encontradas em Teixeira et al. (2013). algoritmo SAFER possui a vantagem de necessitar de poucas informações da superfície para estimar os parâmetros biofísicos da superfície utilizando dados de sensoriamento remoto, possibilitando um detalhamento espacial das variáveis.

\section{RESULTADOS E DISCUSSÃO}

Na Figura 2, observa-se a classificação supervisionada utilizando o algoritmo MaxVer (Máxima Verossimilhança). Na tonalidade verde, observa-se área ocupada por floresta, em azul está representado o corpo d'água (Rio Tapajós) e as áreas em marrom, referem-se às áreas com atividade agrícola e pecuária (agropastoril), predominantemente ocupado por arroz, soja e pastagem. No entorno da FLONA Tapajós são comuns os desflorestamentos que se iniciam, geralmente, pelo corte seletivo de madeira ou incêndios florestais e, posteriormente, a conversão total da floresta em pasto e, ou, agricultura. Após essas práticas, as áreas são abandonadas, criando um mosaico de cobertura vegetal em diferentes estádios sucessionais (SHIMABUKURO et al., 1998).

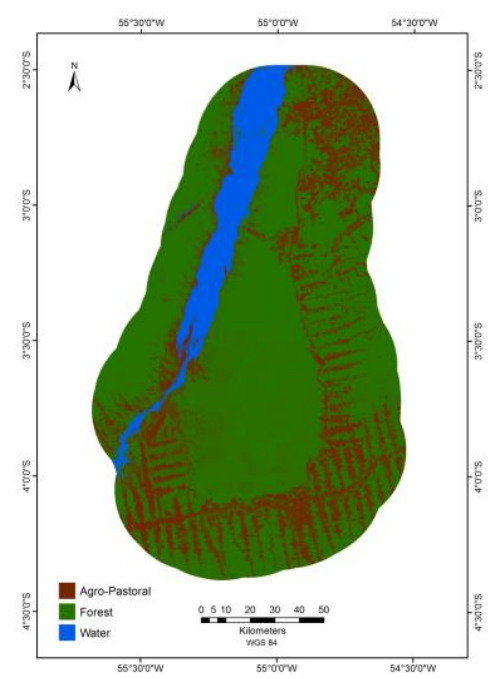

Figura 2. Imagem resultante da classificação digital. 
Na figura 3, observa-se o albedo das áreas agropastoris e Floresta, cujos valores em média foram, 0,23 e 0,14 , respectivamente. As florestas apresentam diferença na coloração da vegetação existente, que por serem mais escuras refletem menos energia que a pastagem. Resultados de albedo na floresta tropical Amazônica foram apresentados por Culf et al., (1995) com valores que variam de 0,1225 a 0,134, respectivamente. Medições de albedo em áreas de pastagem na Amazônia foram feitas por Bastable et al., (1993) e Fisch et al., (1994) tendo-se obtido uma variação de 0,163 e 0,190. Estes valores corroboram com os resultados encontrados por Fisch et al. (1998) com 21,6\% para área de pastagem e 12,5\% na floresta. Observa-se variação do albedo devido às datas diferentes de aquisição das imagens para realização do mosaico, devido à grande presença de nuvens na região. Portanto com as cenas distintas e dados meteorológicos de datas diferentes, consequentemente características ambientais e espectrais das imagens são distintas. Estes resultados corroboram com os obtidos em estudos anteriores que mostram a variação do albedo com o ângulo de elevação solar, cobertura de nuvens, entre outros fatores (LEITÃO et al, 2002).

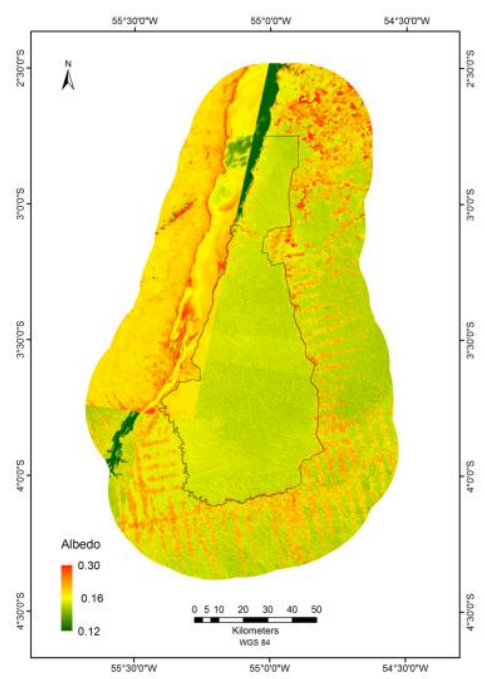

Figura 3. Albedo da área da FLONA Tapajós e buffer de $30 \mathrm{Km}$

A Amazônia é uma das regiões do planeta onde a resposta da circulação atmosférica regional a mudanças do albedo superficial é mais intensa. Estudos de simulação utilizando diversos modelos mostram que a conversão da floresta tropical em pastagem causa uma redução na precipitação local; a qual é principalmente dependente da mudança no albedo da superfície.

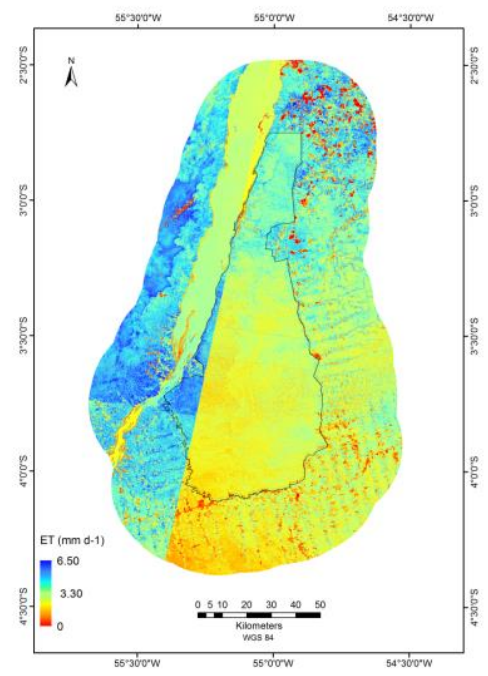

Figura 4. Evapotranspiração na FLONA Tapajós e entorno. 
Na Figura 4, é apresentada a evapotranspiração na área da Flona Tapajós e entorno. Na área da floresta primária, a evapotranspiração diária média foi de $4,78 \mathrm{~mm} \cdot \mathrm{d}^{-1}$ enquanto que nas áreas de agrícolas, observa-se valores médios de $3,38 \mathrm{~mm} \cdot \mathrm{d}^{-1}$. No mosaico, observa-se a junção entre as cenas devido às características ambientais e das imagens serem distintas devido às diferentes datas de aquisição. Estudos realizados com dados das torres de fluxo do Projeto LBA (Large BiosphereAtmosphere) mostraram que a sazonalidade da evapotranspiração na Amazônia é controlada principalmente pela elevada disponibilidade de radiação com pouca influência das condições hídricas (ROCHA et al., 2009).

Importante salientar que as quarto imagens que compõem o mosaico para cobrir toda a área da FLONA e o buffer de $30 \mathrm{~km}$ foram obtidas em período seco na Amazônia, compreendido entre julho a dezembro. Isso ocorre porque no período chuvoso, a presença de nuvens dificulta o imageamento com baixo percentual de nuvens. Tomasella et al. (2007) verificaram que mesmo em período com menor precipitação na Amazônia, as taxas de evapotranspiração mantém-se alta devido ao conteúdo de água no solo. As mudanças de uso da terra acarretam alterações na superfície pois a redução da cobertura vegetal acarreta mudança no albedo, reduzindo a evapotranspiração, alterando os regimes de precipitação e, posteriormente podendo causar mudanças na temperatura e na quantidade de umidade do solo e, consequentemente nas condições ambientais.

\section{CONSIDERAÇÕES FINAIS}

Esta análise preliminar foi realizada para os quatro cenas do satélite Landsat-5/TM que cobrem a Floresta Nacional do Tapajós. Como as datas de aquisição das imagens são diferentes, influenciou o resultado da média de toda a área em função do ângulo diferente de sensor, bem como os dados meteorológicos. Conclui-se que mesmo com baixa densidade de estações meteorológicas na Amazônia, foi possível avaliar a ação antrópica no entorno da FLONA, contribuindo para avaliações dos impactos da expansão agrícola nessa região.

\section{REFERÊNCIAS BIBLIOGRÁFICAS}

BASTABLE, H.G., SHUTTLEWORTH, W.J., DALLAROSA, R.L.G. et al. Odbservations of climate albedo and surface radiation over cleared and undisturbed Amazonian Forest. International Journal Climatology, Chicester, v.13, p.783-96, 1993.

CULF, A. D.; FISCH, G.; HODNETT, M. G. The albedo of Amazonian forest and ranch land. Journal $\begin{array}{llll}\text { Climate. } & \text { p. } & 1544-1554, & \text { http://dx.doi.org/10.1175/1520- }\end{array}$ 0442(1995)008\%3C1544:TAOAFA\%3E2.0.CO;2

DEFRIES, R. S.; BELWARD, A. S. Global and regional land cover characterization from satellite data: an introduction to the Special Issue. International Journal of Remote Sensing, v. 21, n. 6-7, p. 1083-1092, 2000. http://dx.doi.org/10.1080/014311600210083

DIRMEYER, P.A.; BRUBAKER, K.L. 2007. Characterization of the Global Hydrologic Cycle from a Back-Trajectory Analysis of Atmospheric Water Vapor. Journal Hydrometeorology, v. 8, n.1, p.2037, 2007. http://dx.doi.org/10.1175/JHM557.1

FEARNSIDE, P. M. A floresta Amazônica nas mudanças globais. Manaus: INPA, 2003. 134 p.

FISCH, G; MARENGO, J. A.; NOBRE, C. A. Uma Revisão Geral Sobre o Clima da Amazonia. Acta Amazônica, v. 28, n. 2, p. 101-126, 1998.

LEITÃO, M. M. V. B. R.; SANTOS, J. M.; OLIVEIRA, G. M. Estimativas do albedo em três ecossistemas da floresta amazônica. Revista Brasileira de Engenharia Agrícola e Ambiental. v. 6, n. 2, p. 256-261, 2002. http://dx.doi.org/10.1590/S1415-43662002000200013

MACHADO, W. B. Balanço de energia em áreas de floresta e de um campo agrícola no leste da Amazônia. 2012. 66 páginas. Dissertação de Mestrado em Recursos Naturais da Amazônia Programa de Pós-Graduação em Recursos Naturais da Amazônia. Universidade Federal do Oeste do Pará - UFOPA, Santarém, 2012.

PAROTTA, J.A.;FRANCIS, J. K.; ALMEIDA, R. R. Trees of Tapajós: a photografic Field guide. General technical report. United States Departament of Agriculture, Riopiedras, Puerto Rico, 1995. 
ROCHA, H. R. da; GOULDEN, M. L.; MILLER, 1. D.; MENTON, M. C.; PINTO, L.; de FREITAS, H. C.; FIGUEIRA, A. Seazonality of water and heat fluxes over a tropical Forest in eastern Amazonia. Ecological Application, v. 14, n. 4, 2004.

SHIMABUKURO, Y. E. et al. Land cover classification from RADARSAT data of the Tapajós National Forest, Brazil. Canadian Journal of Remote Sensing, v. 24, n. 4, p. 393-401, 1998.

SHIMABUKURO, Y. E.; RUDORFF, B. F. T. Fraction images derived from NOAA AVHRR data for global studies. International Journal of Remote Sensing, v. 21, n. 17, p. 3191-3194, 2000. http://dx.doi.org/10.1080/014311600750019804

SILVER, W.L. et al. Effects of soil texture on bellow-ground carbon and nutrient storage in a lowland and Amazonian forest ecosystem. Ecossystems 3: 193-209, 2000. http://dx.doi.org/10.1007/s100210000019

TEIXEIRA, A. H. DE C.; HERNANDEZ, F. B. T.; LOPES, H. L.; SCHERER-WARREN, M.; BASSOI, L.H. A Comparative Study of Techniques for Modeling the Spatiotemporal Distribution of Heat and Moisture Fluxes in Different Agroecosystems in Brazil. In: George G. Petropoulos. (Org.). Remote Sensing of Energy Fluxes and Soil Moisture Content. 1ed.Boca Raton, Florida: CRC Group, Taylor and Francis, 2013b, p. 169-191.

TEIXEIRA, A. H. de C.; SCHERER-WARREN, M.; HERNANDEZ, F.B.T.; ANDRADE, R.G.; LEIVAS, J.F. Large-Scale Water Productivity Assessments with MODIS Images in a Changing Semi-Arid Environment: A Brazilian Case Study. Remote Sensing, v. 5, p. 5783-5804, 2013. http://dx.doi.org/10.3390/rs5115783

TOMASELlA, J.; HODNETT, M.G.; CUARTAS, L.A.; NOBRE, A.D.; WATERLOO, M.J.; OLIVEIRA, S.M. The water balance of an Amazonian micro-catchment: the effect of interannual variability of rainfall on hydrological behaviour. Hydrol. Process., v. 22, p. 2133-2147, 2007. http://dx.doi.org/10.1002/hyp.6813 